\title{
Environmental benefits of bike sharing: a big data-based analysis
}

Yongping Zhang ${ }^{1}$, Zhifu $\mathrm{Mi}^{2,,+}$

1. The Bartlett Centre for Advanced Spatial Analysis, University College London, 90 Tottenham Court Road, London W1T 4TJ, UK

2. The Bartlett School of Construction and Project Management, University College London, 1-19 Torrington Place, London WC1E 7HB, UK

Abstract: Bike sharing is a new form of transport and is becoming increasingly popular in cities around the world. This study aims to quantitatively estimate the environmental benefits of bike sharing. Using big data techniques, we estimate the impacts of bike sharing on energy use and carbon dioxide $\left(\mathrm{CO}_{2}\right)$ and nitrogen oxide $(\mathrm{NOx})$ emissions in Shanghai from a spatiotemporal perspective. In 2016, bike sharing in Shanghai saved 8,358 tonnes of petrol and decreased $\mathrm{CO}_{2}$ and $\mathrm{NO}$ x emissions by 25,240 and 64 tonnes, respectively. From a spatial perspective, environmental benefits are much higher in more developed districts in Shanghai where population density is usually higher. From a temporal perspective, there are obvious morning and evening peaks of the environmental benefits of bike sharing, and evening peaks are higher than morning peaks. Bike sharing has great potential to reduce energy consumption and emissions based on its rapid development.

Keywords: bike sharing, sharing economy, energy consumption, carbon emissions, air pollution, big data

\footnotetext{
Corresponding author at: The Bartlett School of Construction and Project Management, University College London, 1-19 Torrington Place, London WC1E 7HB, UK

E-mail addresses: z.mi@ucl.ac.uk (Z.Mi)

${ }^{\dagger}$ Yongping Zhang and Zhifu Mi contributed equally to this work.
} 


\section{Introduction}

Although bike sharing is a relatively new form of transport in urban areas, it has become increasingly popular in towns and cities around the world in recent years $\left(\mathrm{O}^{\prime}\right.$ Brien et al., 2014). Bike sharing is an oriented production service system (PSS) where ownership of the bike is retained by the provider, who sells the functions of the bike, via modified distribution and payment systems (Annarelli et al., 2016; Mont, 2002; Piscicelli et al., 2015). This popularity can be mainly explained by the fact that bikesharing programmes are associated with various social, environmental, and economic benefits, such as a decrease in carbon dioxide $\left(\mathrm{CO}_{2}\right)$ emissions, a reduction in various diseases (e.g., diabetes and obesity), and a decline in traffic congestion and noise pollution through the provision of alternatives to auto-commuting and an increase in public transit use (Caulfield et al., 2017; Martens, 2007; Mont, 2004).

The existing bike-sharing literature can be mainly grouped into two domains (Médard de Chardon and Caruso, 2015). The first domain includes mathematical models that focus on rebalancing. For example, taking London's Barclays Cycle Hire programme as a study case, Pfrommer et al. (2014) considered the efficient operation of shared mobility systems via the combination of intelligent routing decisions for staff-based vehicle redistribution and real-time price incentives for customers. Forma et al. (2015) proposed a 3-step mathematical programming-based heuristic method for the static repositioning problem. In addition, Pal and Zhang (2017) presented a novel mixed integer linear programme for solving real-life large-scale static rebalancing problems. The studies in the second domain include those that characterise bike sharing through various analyses. For example, Wood et al. (2011) visualised the dynamics of London's bike-sharing scheme using flow maps, and Zaltz Austwick et al. (2013) employed 
visualisation, descriptive statistics and spatial and network analysis tools to explore usage in five cities around the world. Beecham et al. (2014) proposed a new technique for classifying commuting behaviours that involves various spatial analysis algorithms and visual analytics techniques. In addition, Caulfield et al. (2017) examined usage patterns of a bike-sharing programme in Cork, a medium-sized city in Ireland. This research provides insights into the dynamics of a relatively small bike-sharing scheme and presents results on how bike sharing has offered citizens a new transport alternative. Some researchers have a particular interest in understanding the factors that affect bike sharing (such as the built environment, weather, and socio-economic demographics) (Bachand-Marleau et al., 2012; El-Assi et al., 2017; Faghih-Imani et al., 2014). Most of the existing studies focus on the analysis of an individual city, such as London (the UK) (Ogilvie and Goodman, 2012; Pfrommer et al., 2014; Wood et al., 2011), Washington DC (the United States) (Buck et al., 2013; Buehler, 2012), Toronto and Montreal (Canada) (Fuller et al., 2011; Habib et al., 2014), and Hangzhou and Zhongshan (China) (Chen et al., 2017; Shaheen et al., 2011; Zhang et al., 2017). However, some studies have performed a comparative analysis of the bike-sharing systems in different cities. These comparisons are based on numerous aspects, such as the number of subscribers/stations/bikes, modal share changes, connectivity, and flows (O’Brien et al., 2014; Zaltz Austwick et al., 2013; Zhang et al., 2015).

However, despite acknowledgement that bike sharing results in various environmental benefits, no studies have directly estimated the environmental benefits of bike sharing. A key contribution of this paper, therefore, is to fill this research gap using a big data technique to quantitatively estimate the impacts of bike sharing on energy savings and emission reductions.

Since the introduction of the first bike-sharing programme in the 1960s, bike-sharing 
service has evolved quickly over a half century (DeMaio, 2009; El-Assi et al., 2017; Shaheen et al., 2013). We are now facing a new generation of bike sharing, referred to as the dockless (or station-less) bike-sharing service, which is currently emerging in China and expanding around the world. Before the existence of the dockless bikesharing service, bikes needed to be docked at stations, whereas in this emerging service, bikes can be unlocked and paid for using a smartphone and can be picked up and left any authorised parking area at users' convenience. The first such service was launched in June 2015 by the start-up company ofo. According to the Research Report on Bikesharing Employment (The Centre for Sharing Economy, 2017), released in September 2017 by China's National Information Centre, the company now has approximately 8 million yellow-framed bikes in more than 170 cities in 9 countries. It has approximately 25 million orders per day and now has 3 billion cumulative orders. The Research Report also shows that at present, there are approximately 16 million dockless bikes in China and 50 million orders per day. In addition, the rapid development of this dockless bikesharing service has created 100,000 new jobs in China. In particular, 70,000 new jobs were created in the first half of 2017. Because this bike-sharing service is very new, we could only find one existing study: Bao et al. (2017) proposed a data-driven approach to develop bike lane construction plans based on bike trip data, provided by Mobike, ofo's main competitor and the world's largest dockless bike-sharing company.

In this paper, we quantitatively evaluate environmental benefits of bike sharing using a large-scale bike-sharing dataset provided by the company Mobike. We estimate the impacts of bike sharing on energy use and $\mathrm{CO}_{2}$ and $\mathrm{NO}$ x emissions in Shanghai in 2016. Using a big data technique, we discuss the environmental benefits from a spatiotemporal perspective.

\section{Data and methods}




\subsection{Study area and data}

With an area of $6,341 \mathrm{~km}^{2}$ and a population of 24.26 million, Shanghai is one of the largest cities in the world and China's economic centre (Fig. 1a). Shanghai's GDP in 2016 was 2.8 trillion Yuan, accounting for 3.6\% of China's total GDP (National Bureau of Statistics, 2017). Huangpu, Putuo, Hongkou, Jingan, Changning, Yangpu, and Xuhui districts are regarded as old central area among Shanghai's sixteen districts. Lujiazui, Shanghai's CBD (central business district), is located in Pudong New District and adjacent to old central area. Shanghai's Circle Road is a high-speed road surrounding the most part of Shanghai City (excluding Chongming district). As of July 2017, Shanghai had 1.5 million dockless bikes, making it the largest bike-sharing market in the world (Xinmin Evening News, 2017).

The data used here were obtained from Mobike, which provides 'a bike-sharing service to fulfil urban short trips - anytime, to any authorised parking destination - by combining innovation and today's IoT (Internet of Things) technology' (Mobike, 2017). As of March 2017, Mobike had more than 4 million red-framed bikes in nearly 80 cities worldwide. The company receives approximately 20 million orders per day, accounting for $56.56 \%$ of the total market, making it the largest dockless bike-sharing company in the world (Sohu Financial, 2017). The dataset, provided by Mobike, contains approximately 56.62\% of total trip orders in August 2016. In it, there were 1,023,603 orders made by 306,936 users for 17,688 bikes. Each order contains the basic trip information, namely, the order identification (ID), user ID, bike ID, start time, the longitude and latitude of the origin, end time, the longitude and latitude of the destination(s), and track. Each attribute is a column in the dataset. The attribute track contains the longitudes and latitudes of locations between the start and end locations. For an N-location track, the format of the column track is 'longitude1, latitude1\# longitude2, latitude2\#.... longitudeN, latitudeN\#'. It should be noted that all bikes are GPS tracked. Therefore, a bike trip can be regarded as a collection of chronologically ordered GPS points, for example, $p 1 \rightarrow p 2 \rightarrow \cdots \rightarrow p_{n}$, where each point consists of a geospatial coordinate set and a time stamp such as $p=(x, y, t)$ (Hornsby and Egenhofer, 
2002; Zheng et al., 2009). However, due to privacy issues, the tracks in the dataset were preprocessed by Mobike. Each track contains only a collection of chronologically unordered spatial locations with no temporal information, which means we do not know users' real trip routes. In Section 2.2, we propose a method to solve this issue.

The spatial distribution of the origins and destinations of all bike trips (shown in Fig. 1b) was created using the point density method in ArcGIS, which is developed by ESRI (Environmental Systems Research Institute) and is the world's most widely used commercial GIS (Geographic Information System) software. Most trips occurred in Shanghai's old central area, especially in Yangpu, Hongkou, Jingan, and Huangpu districts. Almost all bikes were used inside Shanghai's Circle Road.

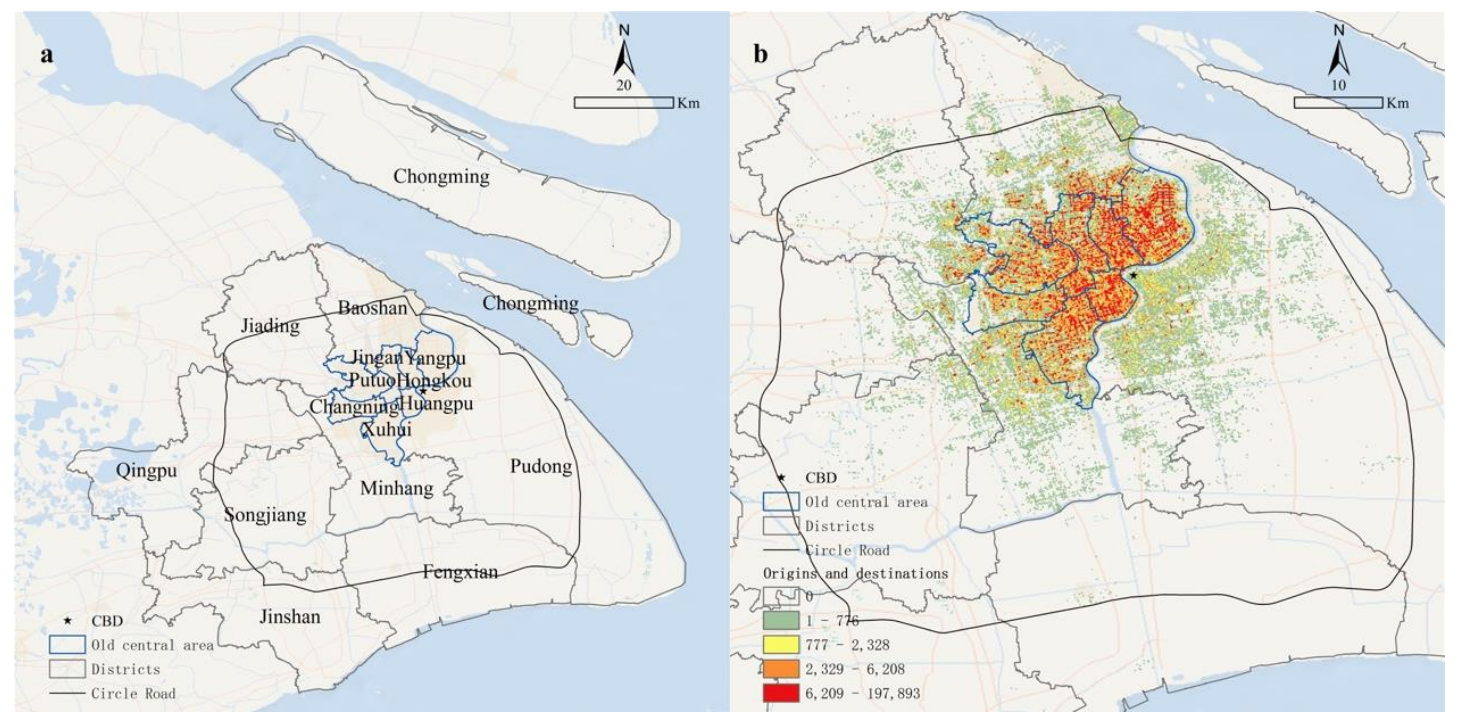

Fig. 1. Shanghai (a) and the distribution of origins and destinations of all bike trips (b). Note: CBD means central business district.

\subsection{Trip distance estimation}

To estimate environmental benefits, we first need to estimate the distances of the bike trips. The bike-sharing data from traditional dock-based services only contain the 
longitudes and latitudes of the origin and destination stations. Consequently, the trips have to be represented as a straight line between the origins and destinations, and the trip distances are calculated using a Euclidean distance between the origins and destinations. Considering the bike-sharing data used here also contain the spatial information of the origin and destination locations, we can also calculate the trip distance using a Euclidean distance between the origin and destination. However, this calculation method will underestimate the trip distance. To estimate travel distance more accurately, we propose a method to estimate the trip distances by utilising the track information in our dataset.

Assume a chronologically unordered trip $T_{u}$ can be represented using a collection of chronologically unordered $n$ locations $\left\{l_{1}, l_{2}, \ldots, l_{n}\right\} . l_{1}$ and $l_{n}$ are the trip's origin and destination, respectively. $l_{i}(1<i<n)$ is the spatial location between $l_{1}$ and $l_{n}$ for trip $T_{u}$. The following method is used to retrieve chronologically ordered trip $T_{O}$ from trip $T_{u} . T_{O}$ is initially set as \{\} .

1. Append $l_{1}$ to $T_{O}$, remove $l_{1}$ from $T_{u}$, and set $l=l_{1}$;

2. Find $l^{\prime}$ s closest location $l_{c}$ from $T_{u}$;

3. Append $l_{c}$ to $T_{O}$ and remove $l_{c}$ from $T_{u}$;

4. If $l_{c}=l_{n}, T_{O}$ is the final chronologically ordered trip; however, if $l_{c} \neq l_{n}$, set $l=l_{c}$, and repeat Steps 2-4.

After retrieving the chronologically ordered trip, we can easily calculate its distance by summing all the distances between the various locations.

\subsection{Estimation of vehicle fuels and emissions}

We assess the overall energy consumption and environmental impacts associated with all stages of fuels (Mi et al., 2017b; Yu et al., 2017). The cycle of vehicle fuels can be divided into two stages: well-to-tank and tank-to-wheels. In this study, we consider exploitation and distribution for the former stage and combustion for the latter stage. 
We set a threshold to calculate the number of vehicle kilometres travelled (VKT) and corresponding fuels saved by bike sharing. If the distance is larger than the threshold, people prefer to take a taxi; otherwise, people opt for the alternative, i.e., walking. The energy consumption of a vehicle is calculated as

$$
N= \begin{cases}0, & \text { if } d<u \\ \frac{d \cdot p \cdot \rho}{\lambda_{e} \cdot \lambda_{t}}, & \text { if } d \geq u\end{cases}
$$

where $N$ is the energy consumption of the vehicle, $d$ is the distance travelled (unit: $\mathrm{km}), \quad p$ is petrol consumption per unit of distance travelled (unit: $\mathrm{L} / \mathrm{km}$ ), $\rho$ is density of petrol (unit: $\mathrm{kg} / \mathrm{L}$ ), and $u$ is the threshold. $\lambda_{e}$ is the efficiency of petrol exploitation, and $\lambda_{t}$ is the efficiency of petrol transport. The efficiencies of petrol exploitation and transportation are set as $87 \%$ and 95\%, respectively (Yu et al., 2017).

Emissions generated from vehicle fuels can be divided into exhaust emissions, such as $\mathrm{CO}_{2}, \mathrm{CO}, \mathrm{NO}_{\mathrm{x}}, \mathrm{PM}_{2.5}$, and $\mathrm{PM}_{10}$, and evaporative emissions, such as hydrocarbon (HC). In this study, we focus on $\mathrm{CO}_{2}$ and $\mathrm{NOx}$. Emissions generated by vehicle fuel consumption are calculated as

$$
E_{i}= \begin{cases}0, & \text { if } d<u \\ d \cdot p \cdot \rho \cdot f_{i} & \text { if } d \geq u\end{cases}
$$

where $E_{i}$ represents emissions from vehicle fuel consumption, and $f_{i}$ represents emission factors associated with vehicle driving for different types of emissions (including $\mathrm{CO}_{2}$ and $\mathrm{NOx}$ ).

In this study, the threshold $(u)$ was set as $1 \mathrm{~km}$, which means that travel orders with trip distances longer than $1 \mathrm{~km}$ were considered to estimate energy saving and corresponding emission reduction. The samples used in this study cover a one-month period in August 2016 for one bike-sharing company (i.e., Mobike). To calculate the total environmental benefits of bike sharing in Shanghai in 2016, the estimation results were divided by the sample ratio (i.e., $56.62 \%$ ), divided by the market shares of the 
company (i.e., $56.56 \%$ ), and multiplied by the number of months (i.e., 12). Notably, Section 3.1 is based on the original sample, i.e., for one month and one company, while Section 3.2 is based on the processed result that represents environmental benefits for one year and for all bike-sharing companies.

\subsection{Carbon emission inventory construction}

We used the Intergovernmental Panel on Climate Change (IPCC) approach (Mi et al., $2017 b$ ) to construct carbon emission inventory at sectoral level for Shanghai city. The $\mathrm{CO}_{2}$ emissions from fossil fuel use are calculated by

$$
C=Y \times N \times H \times O
$$

where $C$ are the $\mathrm{CO}_{2}$ emissions from fossil fuel, $Y$ is the fossil fuel consumption (in physical unit), $N$ is the net calorific value that represents heat released when unit fossil fuel is combusting, $H$ is the carbon content that represents $\mathrm{CO}_{2}$ emit when unit heat is released, and $O$ is the oxygenation that represents oxidization rate of fossil fuel combustion. The values of net calorific value, carbon content, and oxygenation can be obtained from Mi et al. (2016).

\section{Results and discussion}

\subsection{Estimated bike trips}

After retrieving the chronologically ordered trips, we calculated the distances of all trips. We deleted those with a distance longer than $50 \mathrm{~km}$ or a time duration longer than 10 hours. After this process of data cleaning, we obtained 1,023,529 trips. The estimated average trip distance was $2.4 \mathrm{~km}$, with a standard deviation of $2.2 \mathrm{~km}$. The total distance of all bike trips was 2.4 million $\mathrm{km}$. The average travel time was 16.8 minutes, with a standard deviation of 18.5 minutes. The travel time for all bike trips was equivalent to 32.7 years.

The spatial distribution of all bike trips (shown in Fig. 2) was created using the line density method in ArcGIS. Some roads with higher densities of bike trips were clearly observed in the old central area, especially in Yangpu, Hongkou, and Jingan districts. Considering the high demand of bike usage on these roads, transport planners should 
give a higher priority in designing them as planned bicycle routes. Fig. 3 shows the temporal distributions of bike trips using trip start time. The weekdays show a typical commuting pattern: a higher number of bike trips during peak commuting times (between 7 and 8 AM and between 17:00 and 18:00 PM). This result can be explained by the fact that many commuters prefer to use Mobike as a solution for the 'last mile problem'. During weekdays, a small peak was observed at 12 noon, which might be caused by some workers who ride bikes to eating locations near their workplaces. The evening peak time varied more than the morning peak time, indicating that bike users have a more flexible time for the end of their daily work. In regard to the weekend temporal pattern, there is a lower probability distribution of bike trips during peak commuting times but a higher probability distribution in the evening. This result is related to more bike trips associated with leisure-related excursions on the weekends, such as physical exercise or going to parks and shopping malls.

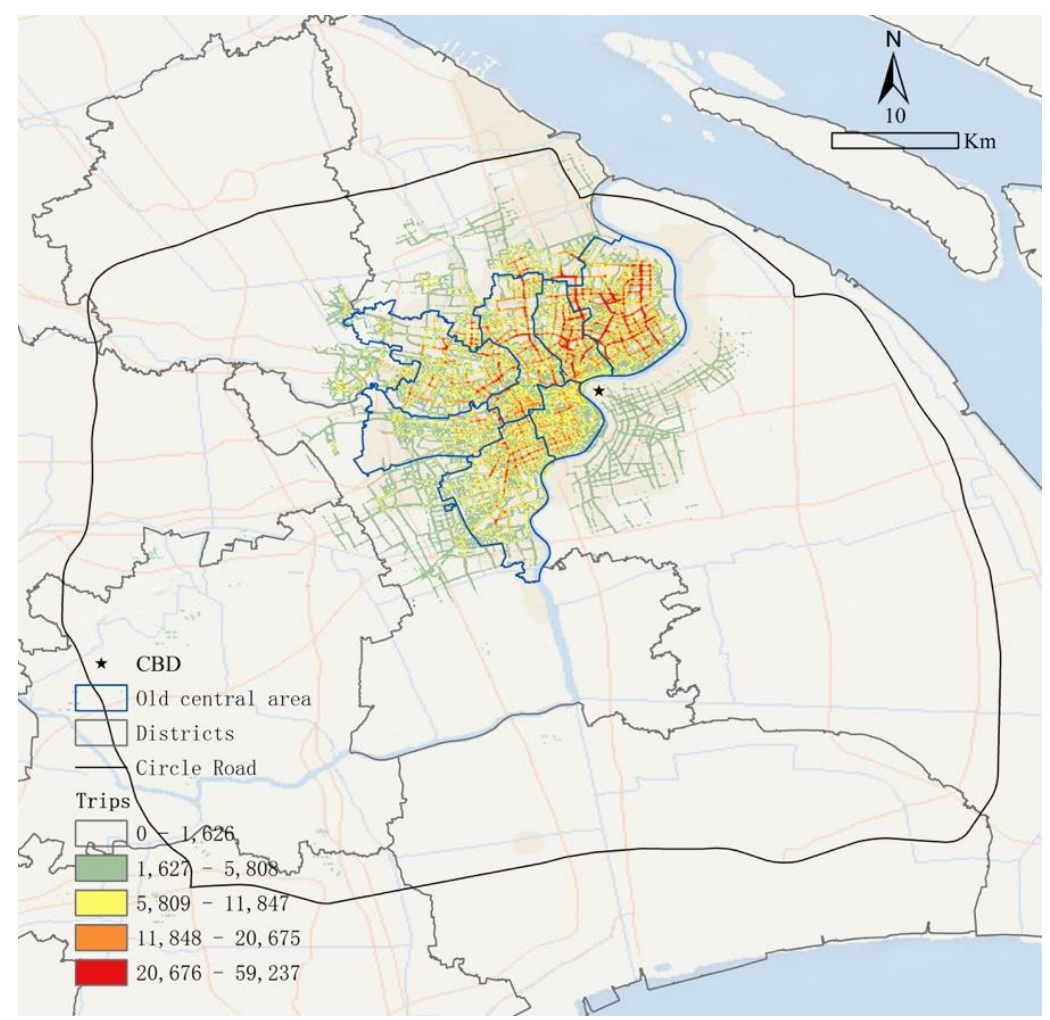

Fig. 2. Spatial distribution of all bike trips.

Note: CBD means central business district. 


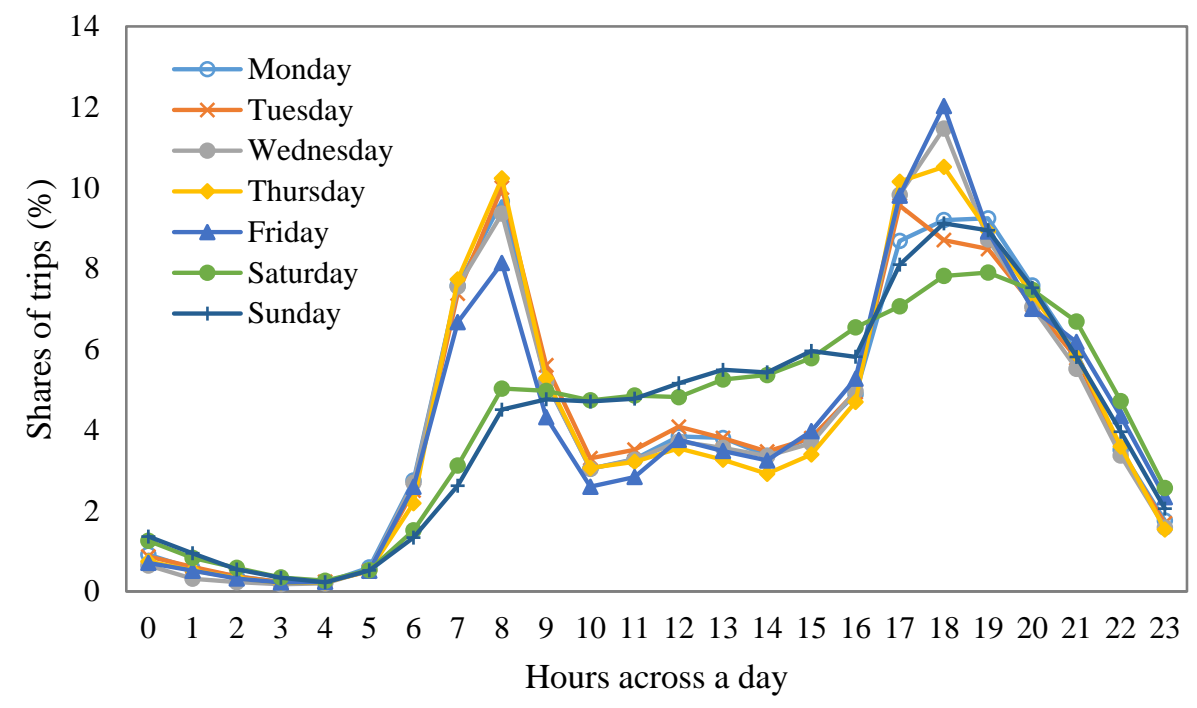

Fig. 3. Temporal distributions of bike trips using trip start time.

\subsection{Environmental benefits of bike sharing}

The transport sector contributes substantially to energy consumption and emissions, especially in developed districts (Mi et al., 2017a, 2017c). As a result of rapid economic growth and increased consumption, the contribution of the transport sector to total emissions in Shanghai increased rapidly during the past decades. In 2000, Shanghai's transport sector emitted 12 million tonnes $(\mathrm{Mt})$ of $\mathrm{CO}_{2}$ emissions, which accounted for $11 \%$ of total emissions. In $2015, \mathrm{CO}_{2}$ emissions from the transport sector increased to $42 \mathrm{Mt}$, which accounted for $24 \%$ of total emissions (Fig. 4). In 2015, the transport sector in Shanghai consumed $20 \%$ of gasoline, $36 \%$ of diesel oil, $96 \%$ of fuel oil, and almost all kerosene. 


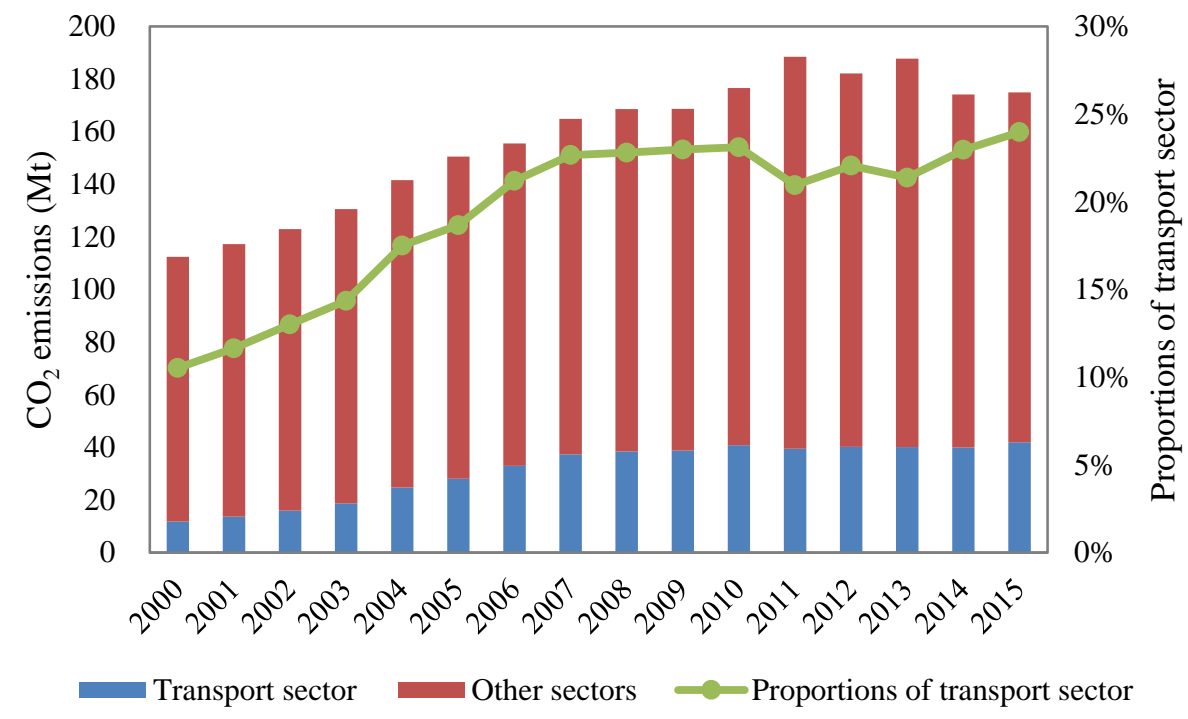

Fig. 4. Carbon emissions from the transport sector in Shanghai from 2000 to 2015.

Bike sharing has considerable potential to save energy and reduce emissions. In 2016, bike sharing in Shanghai saved 8,358 tonnes of petrol and decreased $\mathrm{CO}_{2}$ and $\mathrm{NOx}$ emissions by 25,240 and 64 tonnes, respectively. Fig. 5 demonstrates the spatial distribution of environmental benefits of bike sharing. It can be observed that the environmental benefits are much higher in more developed districts where population density is usually higher. In Shanghai, the density of environmental benefits is highest in Hongkou district. For each square kilometre $\left(\mathrm{km}^{2}\right)$ in this district, bike sharing resulted in a reduction of 33 tonnes of petrol, 100 tonnes of $\mathrm{CO}_{2}$, and 254 kilograms (kg) of NOx in 2016 (Table 1). In fact, Hongkou is the district with the highest population density in Shanghai, i.e., 35,000 people per $\mathrm{km}^{2}$. Therefore, bike sharing in this district resulted in a decrease of $2.9 \mathrm{~kg} \mathrm{CO}_{2}$ emissions per person. In addition, the environmental benefits were relatively high in Huangpu, Yangpu, and Jingan, where energy reduction per $\mathrm{km}^{2}$ exceeded 26 tonnes. 


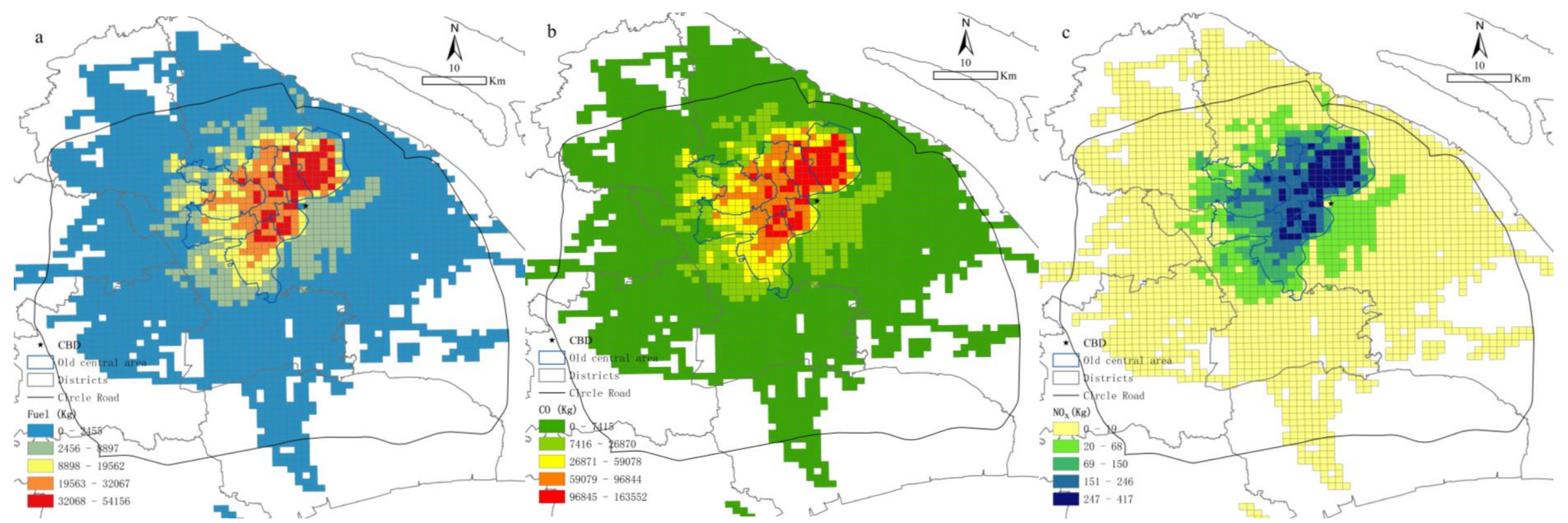

Fig. 5. Spatial distribution of environmental benefits of bike sharing. Sub-figure a, b, and c demonstrate the spatial distribution of energy saving and $\mathrm{CO}_{2}$ and $\mathrm{NOx}$ emission reductions, respectively.

Note: CBD means central business district. 
Table 1 Environmental benefits of bike sharing in administrative districts in Shanghai.

\begin{tabular}{|c|c|c|c|c|c|c|c|c|}
\hline No. & District & $\begin{array}{l}\text { Area } \\
\left(\mathbf{k m}^{2}\right)\end{array}$ & $\begin{array}{c}\text { Fuel } \\
(\mathbf{t})\end{array}$ & $\begin{array}{c}\mathrm{CO}_{2} \\
(\mathrm{t})\end{array}$ & $\begin{array}{c}\mathrm{NO}_{\mathbf{x}} \\
(\mathrm{t})\end{array}$ & $\begin{array}{l}\text { Fuel per unit area } \\
\left(\mathbf{k g} / \mathbf{k m}^{2}\right)\end{array}$ & $\begin{array}{c}\mathrm{CO}_{2} \text { per unit area } \\
\left(\mathrm{kg} / \mathrm{km}^{2}\right)\end{array}$ & $\begin{array}{c}\text { NOx per unit area }_{\left(\mathrm{kg} / \mathrm{km}^{2}\right)} \\
\end{array}$ \\
\hline 1 & Baoshan & 301 & 733 & 2214 & 5.6 & 2433 & 7348 & 19 \\
\hline 2 & Changning & 37 & 409 & 1236 & 3.1 & 10995 & 33205 & 84 \\
\hline 3 & Chongming & 1357 & 0 & 0 & 0 & 0 & 0 & 0 \\
\hline 4 & Fengxian & 721 & 1 & 3 & 0 & 1 & 4 & 0 \\
\hline 5 & Hongkou & 23 & 774 & 2339 & 5.9 & 33087 & 99921 & 254 \\
\hline 6 & Huangpu & 20 & 566 & 1709 & 4.3 & 27609 & 83379 & 212 \\
\hline 7 & Jiading & 463 & 296 & 893 & 2.3 & 638 & 1928 & 5 \\
\hline 8 & Jingan & 37 & 956 & 2888 & 7.3 & 26006 & 78539 & 200 \\
\hline 9 & Jinshan & 595 & 0 & 0 & 0 & 0 & 0 & 0 \\
\hline 10 & Minhang & 373 & 486 & 1469 & 3.7 & 1305 & 3942 & 10 \\
\hline 11 & Pudong & 1397 & 623 & 1882 & 4.8 & 446 & 1347 & 3 \\
\hline 12 & Putuo & 55 & 906 & 2737 & 7.0 & 16330 & 49317 & 125 \\
\hline 13 & Qingpu & 668 & 21 & 63 & 0.2 & 31 & 94 & 0 \\
\hline 14 & Songjiang & 605 & 42 & 128 & 0.3 & 70 & 212 & 1 \\
\hline 15 & Xuhui & 55 & 964 & 2912 & 7.4 & 17478 & 52784 & 134 \\
\hline \multirow[t]{2}{*}{16} & Yangpu & 61 & 1579 & 4769 & 12.1 & 26078 & 78756 & 200 \\
\hline & Shanghai city & 6769 & 8358 & 25240 & 64 & 1235 & 3729 & 9 \\
\hline
\end{tabular}


From a temporal perspective, there are obvious morning and evening peaks of the environmental benefits of bike sharing. Fig. 6 demonstrates the temporal distributions of the reductions in fuel, $\mathrm{CO}_{2}$, and $\mathrm{NOx}$ due to bike sharing over a 24-hour period in Shanghai. It can be observed that the environmental benefits are highest at approximately 18:00 PM. At this time, bike sharing saved 956 tonnes of petrol and decreased $\mathrm{CO}_{2}$ and $\mathrm{NOx}$ emissions in Shanghai by 2,888 and 7,341 $\mathrm{kg}$ tonnes, respectively. The other peak of environmental benefits was observed at approximately 8:00 AM. This temporal distribution is different from that of car sharing, where morning peaks are reported to be higher than evening peaks (Yu et al., 2017).

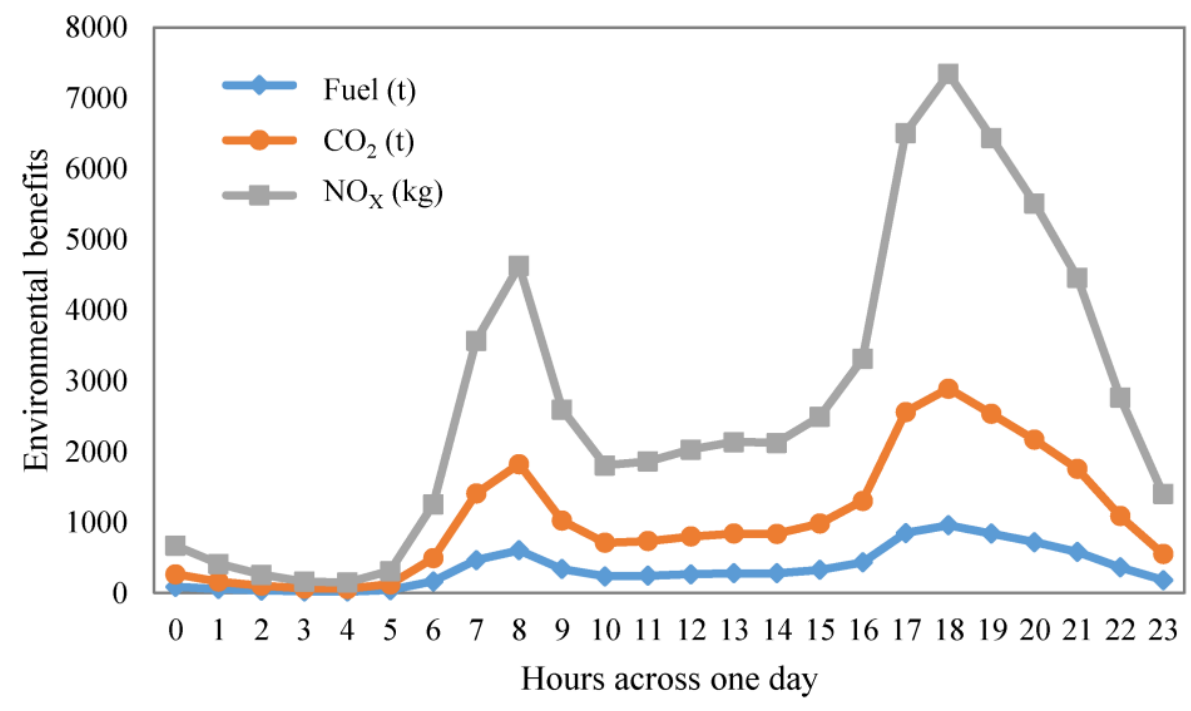

Fig. 6. Temporal distributions of the environmental benefits of bike sharing. The unit for fuel and $\mathrm{CO}_{2}$ is tonne $(\mathrm{t})$, while the unit for $\mathrm{NOx}$ is kilogram $(\mathrm{kg})$.

\section{Conclusions and policy implications}

We used a big data technique to estimate the environmental benefits of bike sharing in Shanghai City from spatial and temporal perspectives. Bike sharing in Shanghai saved 8,358 tonnes of petrol and decreased $\mathrm{CO}_{2}$ and $\mathrm{NO}_{\mathrm{x}}$ emissions by 25,240 and 64 tonnes, respectively, in 2016. From a spatial perspective, environmental benefits were much higher in more developed districts in Shanghai where population density is usually 
higher. The density of environmental benefits was highest in Hongkou district, which has the highest population density in Shanghai City. From a temporal perspective, there were obvious morning and evening peaks of the environmental benefits of bike sharing. The greatest environmental benefits occurred at approximately 18:00 PM followed by 8:00 AM. The findings of this study will be useful for urban transport management, especially for the transformation of low-carbon transport patterns.

The transport sector contributes substantially to energy consumption and emissions. The contributions of the transport sector increase with economic development and lifestyle changes. A sharing economy, such as bike or car sharing, is a potential way to reduce energy use and emissions in the transport sector. Bike-sharing programmes can promote the use of bicycles in cities, which has been demonstrated in numerous studies. As a result, other modes of transport (e.g., private car, taxi, and bus) can be partially replaced by bicycles, especially for the 'last mile problem'. Bike sharing is developing rapidly in many cities worldwide. In China, the use of shared dockless bikes in 2017 is expected to be approximately threefold higher than that in 2016. Accordingly, bike sharing will produce more environmental benefits by reducing energy use and emissions in the transport sector. Besides in China, Currently the dockless bike-sharing has also emerged in other countries, such as the United Kingdom, Singapore and Japan. Our study is able to provide a good reference to the implementation of the dockless bike-sharing service in these countries.

Although this study provides innovative and quantitative estimations of the environmental benefits of bike sharing, there are several limitations. First, due to the privacy issue, the bike-sharing data we obtained were preprocessed by Mobike. Each trip only contained a collection of chronologically unordered spatial locations with no temporal information. Consequently, we could not accurately retrieve a user's real travel route from his/her trip information. In the future, we will attempt to obtain the original GPS-tracked trip data. Based on this dataset, more accurate trips can be retrieved by referring to the work of Zheng et al. (2008). Second, there are uncertainties 
in estimating the environmental benefits of a whole city using data from only one bikesharing company (i.e., Mobike in this study). We calculated the total environmental benefits under the assumption that the environmental benefits correspond to the number of bikes, i.e., the company, location, and weather were ignored. A more accurate estimation will be carried out when the related data become available. Third, it will be meaningful to discuss the relationships between environmental impacts and other socioeconomic factors, such as population, education and prices. These discussions may make the paper more comprehensive and get more useful policy implications.

\section{References}

Annarelli, A., Battistella, C., Nonino, F., 2016. Product service system: A conceptual framework from a systematic review. J. Clean. Prod. 139, 1011-1032. doi:10.1016/J.JCLEPRO.2016.08.061

Bachand-Marleau, J., Lee, B., El-Geneidy, A., 2012. Better Understanding of Factors Influencing Likelihood of Using Shared Bicycle Systems and Frequency of Use. Transp. Res. Rec. J. Transp. Res. Board 2314, 66-71. doi:10.3141/2314-09

Bao, J., He, T., Ruan, S., Li, Y., Zheng, Y., 2017. Planning Bike Lanes based on Sharing-Bikes' Trajectories, in: Proceedings of the 23rd ACM SIGKDD International Conference on Knowledge Discovery and Data Mining - KDD '17. ACM Press, New York, New York, USA, pp. 1377-1386. doi:10.1145/3097983.3098056

Beecham, R., Wood, J., Bowerman, A., 2014. Studying commuting 
behaviours using collaborative visual analytics. Comput. Environ. Urban Syst. 47, 5-15. doi:10.1016/j.compenvurbsys.2013.10.007

Buck, D., Buehler, R., Happ, P., Rawls, B., Chung, P., Borecki, N., 2013. Are Bikeshare Users Different from Regular Cyclists? Transp. Res. Rec. J. Transp. Res. Board 2387, 112-119. doi:10.3141/2387-13

Buehler, R., 2012. Determinants of bicycle commuting in the Washington, DC region: The role of bicycle parking, cyclist showers, and free car parking at work. Transp. Res. Part D Transp. Environ. 17, 525-531. doi:10.1016/j.trd.2012.06.003

Caulfield, B., O’Mahony, M., Brazil, W., Weldon, P., 2017. Examining usage patterns of a bike-sharing scheme in a medium sized city. Transp. Res. Part A Policy Pract. 100, 152-161. doi:10.1016/j.tra.2017.04.023 Chen, M., Wang, D., Sun, Y., Liu, C., Bai, Z., 2017. Service Evaluation of Public Bicycle Scheme from a User Perspective. Transp. Res. Rec. J. Transp. Res. Board 2634, 28-34. doi:10.3141/2634-04

DeMaio, P., 2009. Bike-sharing: History, impacts, models of provision, and future. J. Public Transp. 12, 41-56. doi:10.1016/0965-8564(93)90040$\mathrm{R}$

El-Assi, W., Salah Mahmoud, M., Nurul Habib, K., 2017. Effects of built environment and weather on bike sharing demand: a station level analysis of commercial bike sharing in Toronto. Transportation (Amst). 44, 589-613. doi:10.1007/s11116-015-9669-z 
Faghih-Imani, A., Eluru, N., El-Geneidy, A.M., Rabbat, M., Haq, U., 2014. How land-use and urban form impact bicycle flows: Evidence from the bicycle-sharing system (BIXI) in Montreal. J. Transp. Geogr. 41, 306-314. doi:10.1016/j.jtrangeo.2014.01.013

Forma, I.A., Raviv, T., Tzur, M., 2015. A 3-step math heuristic for the static repositioning problem in bike-sharing systems. Transp. Res. Part B Methodol. 71, 230-247. doi:10.1016/j.trb.2014.10.003

Fuller, D., Gauvin, L., Kestens, Y., Daniel, M., Fournier, M., Morency, P., Drouin, L., 2011. Use of a new public bicycle share program in Montreal, Canada. Am. J. Prev. Med. 41, 80-83. doi:10.1016/j.amepre.2011.03.002

Habib, K.N., Mann, J., Mahmoud, M., Weiss, A., 2014. Synopsis of bicycle demand in the City of Toronto: Investigating the effects of perception, consciousness and comfortability on the purpose of biking and bike ownership. Transp. Res. Part A Policy Pract. 70, 67-80. doi:10.1016/j.tra.2014.09.012

Hornsby, K., Egenhofer, M.J., 2002. Modeling Moving Objects over Multiple Granularities. Ann. Math. Artif. Intell. 36, 177-194.

Martens, K., 2007. Promoting bike-and-ride: The Dutch experience. Transp. Res. Part A Policy Pract. 41, 326-338. doi:10.1016/J.TRA.2006.09.010

Médard de Chardon, C., Caruso, G., 2015. Estimating bike-share trips 
using station level data. Transp. Res. Part B Methodol. 78, 260-279. doi:10.1016/j.trb.2015.05.003

Mi, Z., Meng, J., Guan, D., Shan, Y., Liu, Z., Wang, Y., Feng, K., Wei, Y.M., 2017a. Pattern changes in determinants of Chinese emissions. Environ. Res. Lett. 12, 74003. doi:10.1088/1748-9326/aa69cf

Mi, Z., Meng, J., Guan, D., Shan, Y., Song, M., Wei, Y.-M., Liu, Z., Hubacek, K., 2017b. Chinese CO2 emission flows have reversed since the global financial crisis. Nat. Commun. 8, 1712. doi:10.1038/s41467-017-01820-w

Mi, Z., Wei, Y.M., Wang, B., Meng, J., Liu, Z., Shan, Y., Liu, J., Guan, D., 2017c. Socioeconomic impact assessment of China's CO2 emissions peak prior to 2030. J. Clean. Prod. 142, 2227-2236. doi:10.1016/j.jclepro.2016.11.055

Mi, Z., Zhang, Y., Guan, D., Shan, Y., Liu, Z., Cong, R., Yuan, X.C., Wei, Y.M., 2016. Consumption-based emission accounting for Chinese $\begin{array}{llll}\text { cities. } & \text { Appl. } & \text { Energy } & 184,\end{array}$ doi:10.1016/j.apenergy.2016.06.094

Mobike, 2017. About Mobike. Rrl: https://mobike.com/uk/about.

Mont, O., 2004. Institutionalisation of sustainable consumption patterns based on shared use. Ecol. Econ. 50, 135-153. doi:10.1016/J.ECOLECON.2004.03.030

Mont, O.., 2002. Clarifying the concept of product-service system. J. 
Clean. Prod. 10, 237-245. doi:10.1016/S0959-6526(01)00039-7

National Bureau of Statistics, 2017. China Statistical Yearbook 2017. China Statistics Press, Beijing.

O’Brien, O., Cheshire, J., Batty, M., 2014. Mining bicycle sharing data for generating insights into sustainable transport systems. J. Transp. Geogr. 34, 262-273. doi:10.1016/j.jtrangeo.2013.06.007

Ogilvie, F., Goodman, A., 2012. Inequalities in usage of a public bicycle sharing scheme: Socio-demographic predictors of uptake and usage of the London (UK) cycle hire scheme. Prev. Med. (Baltim). 55, 40-45. doi:10.1016/j.ypmed.2012.05.002

Pal, A., Zhang, Y., 2017. Free-floating bike sharing: Solving real-life largescale static rebalancing problems. Transp. Res. Part C Emerg. Technol. 80, 92-116. doi:10.1016/j.trc.2017.03.016

Pfrommer, J., Warrington, J., Schildbach, G., Morari, M., 2014. Dynamic Vehicle Redistribution and Online Price Incentives in Shared Mobility Systems. IEEE Trans. Intell. Transp. Syst. 15, 1567-1578. doi:10.1109/TITS.2014.2303986

Piscicelli, L., Cooper, T., Fisher, T., 2015. The role of values in collaborative consumption: insights from a product-service system for lending and borrowing in the UK. J. Clean. Prod. 97, 21-29. doi:10.1016/J.JCLEPRO.2014.07.032

Shaheen, S., Cohen, A., Martin, E., 2013. Public Bikesharing in North 
America. Transp. Res. Rec. J. Transp. Res. Board 2387, 83-92. doi:10.3141/2387-10

Shaheen, S., Zhang, H., Martin, E., Guzman, S., 2011. China's Hangzhou Public Bicycle. Transp. Res. Rec. J. Transp. Res. Board 2247, 33-41. doi:10.3141/2247-05

Sohu Financial, 2017. The market share of Mobike is approaching 60\%. url: http://business.sohu.com/20170517/n493354558.shtml.

The Centre for Sharing Economy, 2017. The Research Report on Bikesharing Employment.

Wood, J., Slingsby, A., Dykes, J., 2011. Visualizing the dynamics of London's bicycle hire scheme. Cartogr. Int. J. Geogr. Inf. Geovisualization 46, 239-251. doi:10.3138/carto.46.4.239

Xinmin Evening News, 2017. 1.5 millions: Shanghai is facing a rapid increase of sharing bikes. Xinmin Evening News.

Yu, B., Ma, Y., Xue, M., Tang, B., Wang, B., Yan, J., Wei, Y.M., 2017. Environmental benefits from ridesharing: A case of Beijing. Appl. Energy 191, 141-152. doi:10.1016/j.apenergy.2017.01.052

Zaltz Austwick, M., O’Brien, O., Strano, E., Viana, M., 2013. The Structure of Spatial Networks and Communities in Bicycle Sharing Systems. PLoS One 8, e74685. doi:10.1371/journal.pone.0074685

Zhang, L., Zhang, J., Duan, Z.Y., Bryde, D., 2015. Sustainable bike-sharing systems: Characteristics and commonalities across cases in urban 
China. J. Clean. Prod. 97, 124-133. doi:10.1016/j.jclepro.2014.04.006

Zhang, Y., Thomas, T., Brussel, M., van Maarseveen, M., 2017. Exploring the impact of built environment factors on the use of public bikes at bike stations: Case study in Zhongshan, China. J. Transp. Geogr. 58, 59-70. doi:10.1016/j.jtrangeo.2016.11.014

Zheng, Y., Li, Q., Chen, Y., Xie, X., Ma, W.-Y., 2008. Understanding mobility based on GPS data, in: Proceedings of the 10th International Conference on Ubiquitous Computing. ACM, pp. 312-321.

Zheng, Y., Zhang, L., Xie, X., Ma, W.-Y., 2009. Mining interesting locations and travel sequences from GPS trajectories, in: Proceedings of the 18th International Conference on World Wide Web - WWW'09. ACM Press, New York, New York, USA, p. 791. doi:10.1145/1526709.1526816 